КРИЗИС COVID-19

КАК КАТАЛИЗАТОР РАЗРЫВА ЭКОНОМИК США И КИТАЯ

\author{
๑) ЗАЙЦЕВ А.А., ПЯТАЧКОВА А.С., 2021
}

\begin{abstract}
ЗАЙЦЕВ Александр Андреевич, кандидат экономических наук, научный сотрудник, заместитель заведующего сектором международно-экономических исследований Центра комплексных европейских и международных исследований.

Национальный исследовательский университет "Высшая школа экономики", РФ, 101000 Москва, ул. Мясницкая, 20 (alex.zaytsev@hse.ru), ORCID: 0000-0002-5428-709X.
\end{abstract}

ПЯТАЧкОВА Анастасия Сергеевна, заместитель заведующего Азиатско-Тихоокеанским сектором Центра комплексных европейских и международных исследований.

Национальный исследовательский университет "Высшая школа экономики", РФ, 101000 Москва, ул. Мясницкая, 20 (apyatachkova@hse.ru), ORCID: 0000-0001-7319-2371.

Исследование выполнено при финансовой поддержке РФФИ и ЭИСИ в рамках научного проекта № 20-011-31821 “Мегатенденции мирового политического и экономического развития в условиях глобального системного кризиса: модели и стратегии для России".

Зайцев А.А., Пятачкова А.C. Кризис COVID-19 как катализатор разрыва экономик США и Китая. Анализ и прогноз. Журнал ИМЭМО РАН, 2021, № 2, сc. 13-27. DOI: 10.20542/afij-2021-2-13-27

DOI: $10.20542 / a f i j-2021-2-13-27$

УДК: $339(510)+(73)$

Статья поступила в редакцию 09.04.2021.

Статья принята редакцией 01.06.2021

В работе показано, что проявившееся во время пандемии усиление китайскоамериканского соперничества обусловлено не конъюнктурными, а глубинными факторами, связанными с изменением модели экономического развития в КНР, отсутствием компенсационного изменения экономической модели в США и переходом стран к фазе стратегической конкуренции. 2020 год стал лишь катализатором этих процессов. Тем не менее наблюдающееся расхождение (или разрыв, от англ. decoupling) экономических связей между странами на данный момент носит отраслевой, а не всеобъемлющий характер, проявляясь в виде торговой и санкционной войн, конкуренции и ограничительных мер в таких сферах, как технологии, прямые иностранные инвестиции, наука и образование. Расхождение экономик будет постепенным и вместе с тем принесет серьезные последствия всей структуре международных связей.

Ключевые слова: пандемия COVID-19, торговая война, американо-китайские отношения, санкционная война, конкуренция между КНР и США.

В 2020 г. мир стал свидетелем серьезного обострения отношений между двумя крупнейшими экономиками мира - США и КНР. Опасения, что разрыв между сторонами в торговой, технологической, научной и политической сферах станет одним из важнейших факторов, определяющих тренды развития мировой экономики в ближайшие годы, ранее регулярно подтверждались [1].

Ярче всего симптомы противостояния проявились во время кризиса, вызванного пандемией COVID-19, который наложился на предвыборную ситуацию в США - традиционно непростой период для выстраивания отношений с Америкой. Резонансными кейсами стали предложения отдельных сенаторов о внесении в американский Конгресс законопроектов о наделении президента США необходимыми полномочиями для признания Тибета и Гонконга независимыми государствами, а также о введении санкций против лиц, ответственных за 
нарушение ряда обязательств Китая в адрес Гонконга [2]. Возросло американское давление на китайские компании технологического и других секторов. Были введены индивидуальные санкции против отдельных чиновников, ограничительные меры затронули сферу образования, бизнеса, а также распространились на основные "болевые точки" в китайско-американском взаимодействии (в частности, проблемы с соблюдением прав человека в Синьцзян-Уйгурском автономном районе, Гонконге, Тибете, а также вопросы границ и соблюдения "коренных интересов КНР" в Южно-Китайском море и в отношениях с Тайванем). В США в условиях острого предвыборного противостояния сформировался двухпартийный консенсус по поводу необходимости более жесткой политики в отношении КНР [3].

С новой силой вспыхнули дискуссии о процессе разрыва (расхождения, разъединения, от англ. decoupling) между двумя крупнейшими экономиками мира. При этом на текущем этапе его не стоит понимать как всеобъемлющее противостояние и обрыв связей по всем фронтам. Остро разъединение проявляется лишь в отдельных сферах - технологической, научно-образовательной, торговой, а также заметно в виде таких явлений, как попытки решоринга и стремление обеспечить все большую экономическую независимость экономик друг от друга. Сдерживающим фактором в развитии обозначенных тенденций выступают тесная взаимосвязанность КНР и США, а также заинтересованность китайского и американского бизнеса в сотрудничестве вкупе с сохранением и развитием взаимодействия в других сферах [4].

С учетом ранее не наблюдавшейся интенсивности разворачивавшегося противостояния между КНР и США стечение обстоятельств в виде пандемии и американских президентских выборов может выглядеть как причина растущего конфликта между странами. Однако представляется, что 2020 г. явился лишь катализатором долгосрочных процессов расхождения двух экономических лидеров. В подавляющей части работ по данной тематике постепенное расхождение между странами объясняется фактором стратегической конкуренцией обоих государств ${ }^{1}$. В настоящем исследовании мы анализируем более глубинные предпосылки разрыва и показываем, что он был заложен гораздо раньше того, как конкуренция стала заметна. Фундаментальными факторами разрыва экономик США и КНР выступают исчерпание модели их созависимости, глубинные изменения внутреннего развития Китая (в том числе ориентация страны на качественный рост, технологическое развитие и независимость), а сама стратегическая конкуренция - лишь следствие этих структурных перемен.

Анализ выбранной темы проводится в рамках теории неоклассического реализма, поскольку она позволяет учесть как структурные, так и внутренние факторы, влияющие на развитие процесса расхождения экономик КНР и США. В частности, данное исследование опирается на работы таких авторов, как Г. Роуз, А. Фридберг, Р. Гилпин, Р. Швеллер, С. Лобелл, Н.Рипсман, Ф. Закария, Дж. Тальяферро [6;7;8;9;10;11]. В отличие от классического реализма, где главным мотивом государств является обеспечение безопасности, неоклассический реализм предполагает, что государства стремятся получить влияние, которое позволит им реагировать на неопределенность, создаваемую международной анархией, путем обретения контроля и формирования внешней среды. Таким образом, задачей государства будет не максимизация ресурсов, а максимизация влияния [12;13].

Зависимыми переменными данного исследования будут выступать политики КНР и США в отношении расхождения их экономик. Внешняя среда (структура международных отношений, формирующаяся в процессе изменения мирового порядка), а также совокупные возможности государств (относительная сила на мировой арене) рассматриваются в качестве независимых переменных. Фактор пандемии и выборов США выделены как вмешивающиеся переменные: в данной работе ставится задача дать оценку их влиянию на динамику китайско-американского сотрудничества, поскольку именно в 2020 г. произошлозначительное обострение двусторонних отношений.

\footnotetext{
${ }^{1}$ Как русскоязычная, так и англоязычная литература концентрируется на обсуждении содержания санкционного противостояния последних пяти лет, ответных действий Китая и США в сфере экономической и внешней политики и перспектив развития противостояния, а стратегическая конкуренция держав отмечается авторами как основной реальный мотив обострения отношений (см., например, работы А. Ломанова [5], а также С. Дмитриева, Я. Лексютиной, Ч. Квана. Далее они и другие работы цитируются в тексте и представлены в общем списке литературы).
} 
Методологической основой исследования является системный подход, который напрямую соотносится с выбранной теорией неоклассического реализма, что позволило выявить взаимосвязи между структурными и внутренними факторами, определяющими поведение КНР и США. Данный метод позволяет сосредоточиться на выявлении взаимосвязей между различными элементами системы международных отношений, а также определить факторы, оказывающие наибольшее влияние на развитие двусторонних экономических отношений. Кроме того, в работе был использован метод сводных данных в сочетании с анализом документов, статистической информации, выступлений официальных лиц и других источников. Это позволило провести комплексную оценку расхождения экономик двух стран и охарактеризовать особенности протекания процесса разъединения в отдельных сферах.

Работа выстроена в следующей логике. В первой и второй частях статьи проанализированы основные аспекты противостояния двух стран в период до пандемии и во время нее соответственно. Показано, что введенные в период пандемии двусторонние взаимные ограничения не могут объясняться лишь официальной мотивацией администрации США или руководства КНР, а вызваны более глубинными причинами в виде стратегического сдерживания развития Китая. В третьей части обсуждаются фундаментальные причины разрыва двух государств и обосновывается его долгосрочный характер.

\section{ОТ ТОРГОВОЙ ВОЙНЫ И САНКЦИЙ К ПОСТЕПЕННОМУ РАЗРЫВУ ТЕХНОЛОГИЧЕСКИХ СВЯЗЕЙ}

Наличие серьезных противоречий между КНР и США обращало на себя внимание еще в период президентства Б. Обамы. Однако явное обострение начинается с прихода Д. Трампа к власти в 2017 г.: в сфере экономических двусторонних отношений стало практиковаться все больше не декларативных, а действительно чувствительных мер. Постепенно отдельные предпринимаемые сторонами шаги перерастали в торговую и санкционную войну, ограничения сотрудничества в области технологий для электроники и телекоммуникаций, а затем конфронтация стала распространяться и на другие сферы взаимодействия (инвестиции, образование, науку и т.д.). В настоящем разделе мы показываем, что причины противостояния имеют более глубокие корни, чем официальные объяснения США, связанные с угрозами для национальной безопасности.

\section{Торговая война}

Торговая война ведет отсчет с 2018 г. Формальной ее причиной со стороны США называлась острая проблема внешнеторгового дефицита. Это традиционная "болевая точка" для США: в канун развязывания торговой войны, в 2017 г., американский торговый дефицит составлял почти 800 млрд долл., при этом половина этого дефицита приходилась на дисбаланс торговли с Китаем.

Торговая война началась с введения США пошлин на ввоз стали, алюминия и солнечных батарей из Китая и ответных пошлин КНР на сельскохозяйственные товары и ряд продукции машиностроения из США в начале 2018 г. Впоследствии список товаров, попадающих под ограничения, постепенно расширялся и к концу 2019 г. под 25\%-ной пошлиной оказалась половина всего импорта из Китая (250 млрд долл.). Временное перемирие - торговая сделка первой фазы, заключенная в январе 2020 г., в части торговли лишь гарантировала сохранение статус-кво конца 2019 г. без введения новых тарифов и накладывала обязательства на Китай по закупке американской продукции в размере 200 млрд долл. в течение двух лет [14].

Официально США обвиняет Китай в применении “несправедливых торговых практик", однако конкретные претензии, содержащиеся В отчете торгового представителя США [15], заключаются, главным образом, в закрытости китайского рынка для иностранных инвесторов, принуждении американских компаний к трансферу технологий и обвинениях в несанкционированном проникновении и краже информации из компьютерных сетей США. Также критикуется внешняя инвестиционная политика Китая, связанная с систематическим приобретением американских высокотехнологичных активов и интеллектуальной собственности, которая создает для США риски потери технологического лидерства. 
Таким образом, торговая война слабо мотивирована собственно проблемой торгового дефицита США, а имеет в первую очередь стратегические основания. За два года торговой войны общий американский торговый дефицит продолжил расти (с 800 млрд долл. в 2017 г. до 860-880 млрд долл. в 2018-2019 гг.), однако произошли снижение взаимной торговли Китая и США и замена китайских поставщиков другими странами².

\section{Конкуренция в сфере технологий и инвестиционные ограничения}

Именно технологическая составляющая противостояния представляется наиболее существенной с точки зрения последствий для Китая, США и мировой экономики. По мере экономического развития все страны постепенно переходят от заимствования технологий к собственным инновациям. Китай в последние годы как раз вступает в фазу такого перехода в ряде отраслей: по расходам на НИОКР он уже почти догнал США (Второе место в мире, более $20 \%$ всех мировых расходов) и, вероятно, перегонит их в ближайшее десятилетие. Это не может не беспокоить Соединенные Штаты как крупнейшего технологического лидера. В настоящее время электронная отрасль (в составе которой в том числе телекоммуникации, полупроводниковая промышленность, компьютерные технологии, вся бытовая электроника) является главным объектом санкций. Китай - ключевой мировой производитель и экспортер электронной продукции, однако критическим образом зависит от США в области полупроводников (и оборудования для их производства), которые используются во всех товарах данной отрасли.

Конфронтация в этой сфере началась с обвинений в нарушении китайскими компаниями санкционного законодательства США и прав интеллектуальной собственности. В марте 2016 г. Министерством торговли США китайская компания ZTE (второй по величине производитель телекоммуникационного оборудования и мобильных телефонов в КНР) была включена в так называемый список субъектов (Entity List) ${ }^{3}$. ZTE обвинили в реэкспорте американских комплектующих в страны, подпадающие под американские санкции (Иран и КНДР). Однако после ряда разбирательств и выплат более чем двухмиллиардных долларовых штрафов компания была исключена из санкционного списка. Осенью 2018 г. в этот же список попал и китайский производитель микрочипов Fujian Jinhua [16, c. 90].

Официально США объясняли свою позицию угрозами национальной безопасности и опасениями шпионажа со стороны компаний Китая по запросу властей КНР [17]. На этой волне с 2018 г. Вашингтон ввел запрет на использование продукции ряда китайских телекоммуникационных компаний (ZTE, Huawei и др.) правительственными организациями США. Администрация США также призывала собственных граждан и другие страны отказаться от использования оборудования и технологий Китая в сетях $5 G$.

Ограничения продолжали расширяться в 2019 г. В мае 2019 г. "список субъектов" пополнил телекоммуникационный гигант Huawei и 68 аффилированных с ним юридических лиц, а после перечень расширился и на компании из других отраслей:высокотехнологичных материалов, электронику, полупроводники, суперкомпьютеры, авиацию.

Параллельно вводились ограничения на китайские инвестиции в США, затронувшие в первую очередь критические, развивающиеся и основополагающие технологии (emerging and foundational technologies) ${ }^{4}$, важные для национальной безопасности Соединенных Штатов [18]. При этом американские запреты почти полностью совпали с перспективными отраслевыми направлениями развития, обозначенными в стратегическом плане Китая Made in China 2025 (принят в 2015 г.). С 2017 г., из-за запрета со стороны Комитета по иностранным инвестициям США, не состоялся ряд крупных сделок по покупке

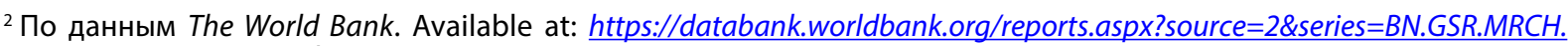
CD\&country=\# (accessed 25.02.2021).

${ }^{3}$ Компании, попадающиевэтотсписок, подлежатэкспортномуконтролю, ипоставки (обычновысокотехнологической) продукции из США в Китай на предприятия из этого списка могут быть запрещены.

${ }^{4}$ К ним относятся: биотехнологии; искусственный интеллект и технологии машинного обучения; навигация; микропроцессорные технологии, в том числе передовые вычислительные технологии или технологии анализа данных; технология квантовой информации и зондирования; аддитивное производство (3D-печать); робототехника; интерфейсы, связывающие головной мозг и компьютер; гиперзвук; современные материалы; передовые технологии наблюдения. Подробнее см. [18].
} 
американских активов китайскими компаниями. Так, под запретом оказались покупка Lattice Semiconductor (полупроводниковые технологии) стоимостью 1.3 млрд долл. в сентябре 2017 г. и Aleris (производство алюминия), оцененная в 1.1 млрд долл. в ноябре 2017 г., и др. В результате приток прямых иностранных инвестиций из Китая в США за 2016-2019 гг. упал в 16 раз (с 53.1 млрд долл. в 2016 г. до 3.3 млрд долл. в 2019 г.5) [19]. При этом в остальную часть мира инвестиции Китая сократились лишь на 23\% [20].

В сфере образования и научного сотрудничества возникли прецеденты неодобрения со стороны США въездных виз для участия китайских представителей в научных конференциях и научном обмене. Для студентов старших курсов, обучающихся по специальностям“робототехника” и“высокотехнологическая промышленность”, сократилась длительность виз с пяти лет до года [21].

В ответ на такое давление Китай форсировал собственные инициативы по обеспечению технологической независимости от США за счет поддержки отраслей, попавших под санкции, а также всерьез озаботился поиском альтернативных источников передовых технологий. В частности, китайские производители полупроводников и разработчики программного обеспечения получили налоговые льготы сроком до пяти лет, ускорились диверсификация поставок (покупка интегральных микросхем компанией Huawei у Японии) и смещение инвестиционного фокуса с США на передовые европейские страны, Израиль и др. [16] Об этом свидетельствуют колоссальные дипломатические усилия, направленные на завершение переговоров по заключению всеобъемлющего инвестиционного соглашения между ЕС и Китаем в конце 2020 г. [22]

Таким образом, если первые санкции, затронувшие телекоммуникационные компании, обосновывались администрацией США преимущественно вопросами национальной безопасности в части сохранности персональных данных, а торговые ограничения - необходимостьюпринуждения Китая к соблюдениюправ интеллектуальной собственности и правилами доступа американских инвесторов на китайский рынок (и объяснения США на первом этапе еще можно было трактовать как убедительные), то последующее расширение санкций на технологический сектор и гораздо более широкий круг сфер и отраслей четко свидетельствует о переходе к стратегическому сдерживанию развития Китая.

\section{ОСОБЕННОСТИ 2020 Г.: ПАНДЕМИЯ И ВЫБОРЫ В США}

\section{Обострение политической риторики}

В экспертной среде возобладало мнение, что пандемия COVID-19, охватившая мир в 2020 г., не была причиной обострения китайско-американских отношений, а лишь послужила триггером для проявления накопившихся противоречий. Признавая правильность данной оценки, тем не менее, сложно не заметить, что указанный период сопровождался беспрецедентным всплеском соперничества двух государств. Одним из самых ярких его проявлений стал срыв торговой сделки между КНР и США, которая до этого обсуждалась почти два года, а в начале января 2020 г., до объявления пандемии, сторонам удалось подписать первую фазу соглашения [23]. Дополнительным дестабилизирующим фактором стало то, что противостояние развивалось на фоне предвыборной президентской кампании в США - традиционно турбулентном периоде для американской политики. Ухудшение отношений заметно отразилось на политической риторике. США обвиняли КНР в распространении COVID-19 и сокрытии информации об этом заболевании, действия Китая, направленные на борьбу с инфекцией, истолковывались как стремление получить преимущества в меняющейся международной обстановке и обеспечить себе лидерство [24].

Наиболее показательной в этом отношении стала речь госсекретаря США М. Помпео в Президентской библиотекеР.Никсона 23 июля 2020г.[25], в которой чиновникобъявилопровале политики вовлечения Китая в либеральный мировой порядок. Характерно, что обе стороны заострили внимание на положительных последствиях случившегося для своих экономик. Так,

${ }^{5}$ В 2020 г. он продолжил сокращаться и составил 1.1 млрд долл. [19] 
бывший заместитель руководителя отдела по международным связам ЦК КПК Чэнь Сяогун заявил, что торговую войну нужно использовать как драйвер позитивных изменений в КНР [26], а тогдашний американский президент Д. Трамп, в свою очередь, подчеркнул, что разрыв с экономикой Китая позволит США сэкономить 500 млрд долл. [27]

Однако параллельно обострению риторики осложнялись и вполне прикладные вопросы взаимодействия двух государств. Стороны даже закрывали дипломатические представительства [28]. После выхода 17 июня 2020 г. Закона о санкциях против Китая за притеснение уйгуров, КНР ввела санкции против четырех американских чиновников [29]. Также в ответ Китай закрепил механизмы санкционной политики на институциональном уровне - в сентябре 2020 г. принято положение "О перечне ненадежных лиц" (Приказ Минкоммерции КНР № 4-2020) [30].

За период, прошедший с начала пандемии, против КНР было выдвинуто беспрецедентное количество ограничительных мер - как по охвату областей китайскоамериканского взаимодействия (торговля, технологическое сотрудничество, сфера образования), так и его участников (компании, университеты, физические лица, чиновники). Де-факто предпринимаемые шаги в основном были направлены на ограничение доступа к иностранным комплектующим, оборудованию или технологиям, а также на закрытие зарубежных рынков для китайских производителей [31].

Помимо расширения санкций для традиционных направлений (сектор ОПК и высокие технологии, в том числе продукция Huawei, NetPosa u CloudWalk Technology, разрабатывающей технологии распознания лиц и систем видеонаблюдения [31]) американские ограничения распространились на более широкий спектр отраслей. Так, были введены санкции против корпораций, работающих в сфере инфраструктуры, строительства и администрирования (China Communications Construction Company, China Shipbuilding Group, одного из крупнейших производственно-строительных предприятий КНР - Синьцзянского производственно-строительного корпуса, попавшего в санкционный лист в связи с ситуацией в Уйгурском районе). Ограничения также затронули китайские мобильные коммуникационные системы, такие как WeChat и TikTok. История о продаже сегмента TikTok США получила международный резонанс [32].

Примечательно, что расширение списка не прекратилось после завершения выборов в США: так, в декабре 2020 г. в список субъектов была включена очередная группа китайских компаний, куда вошли SMIC (крупнейшая китайская и одна из крупнейших в мире в области полупроводниковой продукции) и SZDJI Technology Co Ltd - производитель дронов [33].

Характерно, что обострение отношений между США и Китаем имеет вполне конкретное внешнее проявление. Так, ограничения на использование китайских мобильных приложений были введены в Индии [34] на фоне приграничного конфликта, мобильные операторы в Японии, Индии и Южной Корее объявили об отказе от использования китайского оборудования [35], а Великобритания присоединилась к запрету на использование технологий $5 G$ [36]. При этом считается, что данные решения третьими странами во многом были приняты для сохранения отношений с США. Таким образом, дальнейшее расхождение экономик КНР и США будет иметь значительные последствия для мировой экономики.

Важным пунктом расхождения Пекина и Вашингтона стало различное отношение к участиюв международныхорганизацияхи вовлеченности вмеждународное сотрудничество в целом. США во времена администрации Д. Трампа стали более прагматично подходить как к союзникам, требуя от них равноценного вклада в отношения, так и к собственной роли на многосторонних мировых платформах. Несмотря на формальное возвращение некоторых прежних подходов к сотрудничеству при Дж. Байдене, американская администрация все же вряд ли сможет полноценно вернуться к дотрамповской эпохе. Китай по-прежнему сохраняет открытую позицию и всячески подчеркивает свою готовность к многостороннему взаимодействию. Ярким примером является подписание ВРЭП (Всеобъемлющего регионального экономического партнерства) в ноябре 2020 г., 
поддержка Китаем Всемирной организации здравоохранения (ВО3), продолжение работы в рамках инициативы "Пояса и пути", БРИКС и других платформ.

Хотя китайско-американские противоречия продолжают амортизироваться накопленным потенциалом сотрудничества, в период пандемии тенденции расхождения значительно усилились и перешли на качественно новый уровень, послужив катализатором внутренних реформ и перестройки внешних связей для обоих государств. Так, значительно расширился круг сфер, охваченных санкциями, которые, в свою очередь, получили дополнительное институциональное и нормативное правовое оформление, ужесточилась политическая риторика, ухудшилось качество дипломатических связей, пострадали компании и физические лица. В этом смысле фактор пандемии и сопровождающего ее политического и социально-экономического кризиса значительно ускорил наметившиеся ранее тенденции расхождения США и Китая.

\section{ФУНДАМЕНТАЛЬНЫЕ ФАКТОРЫ РАЗРЫВА}

Может сложиться впечатление, что расхождение КНР и США началось с начала торговой войны. Однако комплексный анализ их взаимоотношений показывает, что при таком подходе видно лишь "верхушку айсберга". Предпосылки расхождения были заложены в сформировавшейся еще в 1980-е годы модели сотрудничества КНР и США, а причины определяются фундаментальными факторами, связанными как с внутренним развитием двух стран, так и ситуацией в мировой экономике в целом. Текущая конъюнктура, например, смена политического руководства в США, может несколько замедлять или временно ограничивать темпы разрыва в отдельных нишах, позволять отдельным корпорациям выиграть время на перестройку производственно-сбытовых цепочек. Но в целом обе страны уже давно и последовательно перестраивают свои экономики и расценивают тесную связь друг с другом как обременение, а не актив.

\section{Изменения в модели развития Китая и созависимости двух экономик}

Обычно для характеристики экономических отношений между КНР и США используют термин "взаимозависимость". Экономист С. Роуч [37] предлагает посмотреть на проблему под другим углом, а именно - как на созависимость.

Созависимость - термин из области психологии, который обозначает патологическое состояние, характеризующееся чрезмерной поглощенностью жизнью другого человека. Созависимые удовлетворяют желания партнера, игнорируя свои интересы и даже действуя в ущерб им. Таким людям также свойственны деструктивные модели поведения, направленные на поддержание зависимости. На пути выздоровления им необходим поиск "своего я", очерчивание здоровых личностных границ и освоение альтернативных поведенческих паттернов. В такой трактовке в китайско-американской модели отношений крылась "мина замедленного действия": изначально это был выгодный симбиоз, но позже к взаимному дополнению и начали добавляться опасные дисбалансы и риски.

С 1980-х годов между Китаем и США начала формироваться модель созависимости экономик [37]. В КНР наблюдался быстрый рост на основе экспортно ориентированной модели, направления в США огромного потока недорогих товаров, который был так нужен Соединенным Штатам для поддержания высокого уровня потребления в условиях замедления роста реальных доходов. США - главный импортер китайских товаров: на них приходится около $20 \%$ всего китайского экспорта, а если учитывать и реэкспорт через Гонконг, то американская доля в экспорте КНР близка к 30\% [38]. Китай соответственно зависел от США как источника экспортных доходов, в особенности динамики потребления. Со временем торговля между странами стала сильно дисбалансированной: дефицит торгового баланса товарами в США вырос почти вчетверо (с 200-300 млрд долл. в конце 1990-х до 837 млрд долл. в 2006 г. и 864 млрд - в 2019 г. [39]), при этом в 2010-е годы около половины этого дефицита стало объясняется дисбалансом торговли с Китаем. В результате в США сформировалась хроническая проблема торгового баланса и крупнейшего в мире государственного долга (9 трлн долл. в 2008 г. и порядка 27 трлн долл. в 2020 г., более 100\% ВВП [40]). 
В Китае же зеркально формировался огромный профицит счета текущих операций, и эту проблему он решал за счет инвестирования в американские, в том числе, государственные ценные бумаги, став в итоге ключевым кредитором США и крупнейшим в мире держателем доллара в золотовалютных резервах. Такой приток капитала поддерживал низкие процентные ставки в США и создавал благоприятные условия для внутренних и внешних заимствований, а также роста финансовых рынков, которые часто превращались в "мыльные пузыри".

Возможность легкого кредитования, а также получения дохода на финансовых рынках привели к формированию в США модели потребления, не основанной на росте реальных зарплатных доходов. Норма личных сбережений в США снизились до рекордно низких уровней с $10-12 \%$ в начале $1980-x$ до $2-4 \%$ располагаемого дохода во второй половине 2000-х годов. В Китае же экспортно ориентированная модель роста сочеталась с высоким уровнем национальных сбережений (порядка 45-50\% ВВП), а также личных сбережений порядка 20-30\% от располагаемого дохода в 2000-е годы [41], и активным заимствованием зарубежных технологий как за счет привлечения иностранных инвесторов на условиях создания совместных предприятий, так и (в 2000-е годы) на основе покупки иностранных активов.

Для Китая технологическая сторона сотрудничества является одной из наиболее важных. США для него - ключевой источник передовых технологий и высокотехнологичного импорта. Высока связанность в научно-исследовательской (в особенности в естественных науках) и образовательной сферах.

Созависимость экономик достигла своего апогея к 2007-2008 гг., началу "великой рецессии", и после начала меняться. КНР инициировал постепенную перестройку модели развития с внешнего спроса, как фактора роста, на внутренний. Появились признаки формирования в этой стране крупнейшего в мире потребительского рынка. За счет быстрого экономического роста последних десятилетий существенно выросло благосостояние местного населения. Только в 2000-е и 2010-е годы средний годовой уровень зарплат вырос более чем на порядок в долларовом эквиваленте - с 1 тыс. долл. (2.8\% от уровня США) в 2001 г. до 11 тыс. долл. (19\% от уровня США) в 2018 г. [42; 43]. Это способствовало росту внутреннего потребления в Китае в том числе и спросу на импорт товаров и услуг. В результате за последние 10 лет за счет формирования огромного спроса на зарубежные поездки (и соответственно отрицательного баланса услуг) профицит текущего счета Китая сократился в долларовом выражении вчетверо (с 420 млрд долл. в 2008 г. до 102.9 млрд долл. в 2019 г.), а в \% ВВП в 9 раз (с 9.1\% ВВП в 2008 г. до 0.7\% ВВП в 2019 г. [44]). Это снизило потребность в компенсационном выводе финансовых ресурсов из КНР (покупке американских ценных бумаг, включая государственные долговые облигаций), что соответственно повлияло на устоявшуюся модель взаимодействия двух крупнейших экономик. По сути внутренний рост потребления и в том числе активный импорт услуг снизили необходимость вывода излишнего свободного финансового капитала за рубеж.

В результате приток финансового капитала из Китая в США начал постепенно сокращаться, что в долгосрочном периоде может создать давление на процентные ставки, проблемы финансирования растущего долга и поддержание устоявшейся модели потребления, основанной на кредитовании и низких сбережениях. Для Китая в долгосрочной перспективе это означает постепенное снижение значимости американского рынка как потребителя и драйвера роста его экспорта. Так, если в 2000-е годы до "великой рецессии" доля США в структуре экспорта Китая (без учета Гонконга) составляла 23-25\%, то в 20082018 гг. она снизилась до 18-19\%, по данным Observatory of Economic Complexity [45]. Таким образом, началось постепенное естественное "расплетение" торговых связей.

В то же время "благополучный Китай" уже менее интересен для иностранных компаний: стремительный рост зарплат в Китае постепенно ослабляет его привлекательность для них. При создании новых предприятий они отдают предпочтение уже другим странам Азии.

Кроме того, произошли важные сдвиги и в мировой экономике. После глобального финансового кризиса 2008-2009 гг. изменилось соотношение динамики мировой торговли 
и ВВП: теперь по темпам роста мировая торговля отстает от мирового ВВП, что снижает ее привлекательность как фактора экономического роста 6 . В то же время усугубился кризис существующей системы международных институтов (ООН, ВТО и др.).

Для Китая эти изменения еще до обострения отношений с США свидетельствовали о необходимости перестройки своей экономики и выработки стратегии с опорой на внутренний спрос и бо́льшую независимость. Такие тенденции находили отражение в основных приоритетах и планах экономического развития КНР последних лет, но особый акцент получили в последнем пятилетнем плане, принятом в октябре 2020 г. В его основу положена концепция "двойной циркуляции", предполагающая развитие с опорой на внутренние источники роста ("внутренняя циркуляция"), при сохранении важной роли международного сотрудничества ("внешней циркуляции"). Основной упор в пятилетке сделан на качественный рост, углубление реформ и открытость внешнему миру, инновационное развитие, расширение внутреннего рынка, совершенствование технологий, возрождение села и оптимизацию урбанизации, выравнивание внутрирегиональных различий, экологические вопросы, повышение благосостояния населения [46].

Таким образом, внутренние изменения в Китае в виде снижения сбережений и роста потребления меняют устоявшуюся модель связи с США, сокращая поток финансовых ресурсов из Китая. Это подрывает сложившуюся в США модель потребления, создает неопределенность перспектив роста американского рынка и соответственно в долгосрочном периоде делает его менее привлекательным для Китая. Возникает необходимость поиска новых быстрорастущих рынков для сбыта китайской продукции. Все это создает глубинные предпосылки постепенного расхождения в торговой сфере, и ставит экономику США перед необходимостью изменения собственной модели.

\section{Экономическая модель США - необходимость перестройки}

Внутренней проблемой США остаются дефицит текущего счета операций и растущий государственный долг. С макроэкономической точки зрения дефицит текущего счета также означает слишком низкий уровень внутренних сбережений в сравнении с инвестициями. В США частные сбережения до 2019 г. были на критически низких уровнях (по данным Бюро экономического анализа США, 2-5\% располагаемого дохода до 2008 г. и 6-7\% после) из-за избыточного потребления, а государственные сбережения (представляющие баланс бюджета) - и вовсе стабильно отрицательные. Очевидно, что бесконечно долго такая ситуация длится не может и перед США встанет вопрос сокращения этого дисбаланса, который обостряется на фоне структурных изменений в Китае. Потребуются сокращение потребления и темпов накопления госдолга и соответственно увеличение внутренних сбережений. Это снизило бы зависимость США от притока финансовых ресурсов из Китая.

Пандемия, возможно, станет как раз тем триггером, который повлияет на изменение стабильно низкого уровня внутренних сбережений в США и тем самым ускорит разрыв созависимости экономик. Так, в среднем за 2020 г. уровень сбережений вырос до $17.3 \%$ располагаемого дохода (при этом в течение года они доходили до 33.7\%) и это в два-три раза выше уровней последних 25 лет [47]. Конечно, такой рост в первую очередь связан с масштабными антикризисными программами поддержки населения и сокращением расходов на различные услуги и туризм во время локдауна. Однако пандемия все же может надолго оставить свой след в паттернах потребления. Негативный опыт текущего кризиса и рост безработицы в США до рекордных со времен Великой депрессии уровней, возможно, сформируют более рациональное отношение к формированию сбережений.

Пока же США не решают проблем отмеченных структурных дисбалансов, а пытаются выйти из кризиса обычными симптоматическими методами: огромными бюджетными вливаниями (антикризисные планы финансовой помощи Трампа и план Байдена) и

${ }^{6}$ По темпам роста мировая торговля отстает от ВВП: за 2012-2019 гг. средние темпы роста торговли товарами и услугами не превышали темпов роста ВВП (по данным IMF, WEO October 2020. Подробнее см.: https://www.imf.org/ en/Publications/WEO/Issues/2020/09/30/world-economic-outlook-october-2020), а если учесть 2020 г., то будут в 1.5 раза ниже (1.7\% - динамика торговли и $2.6 \%$ - динамика мирового ВВП). 
связанным с ними ростом госдолга до 131\% ВВП в 2020 г. [40], масштабной программой количественного смягчения и перегреванием фондовых рынков. Такой подход только позволяет временно сохранить неустойчивую экономическую модель США и усложняет решение проблем в будущем.

\section{Стратегическая конкуренция как фактор разрыва}

Другой, наряду с исчерпанием модели созависимости, фундаментальной причиной американо-китайских противоречий и санкционного давления является переход держав (в первую очередь США) к стратегической конкуренции. При этом она является логичным следствием быстрого экономического и технологического становления Китая. В 2014 г. Китай стал крупнейшей мировой экономикой по ВВП, измеренных в ППС, а в текущих долларах превысил порог в $60 \%$ от ВВП США - тот уровень, по достижении которого Соединенные Штаты стали применять политику сдерживания в отношении Японии в 1990-е годы [12, р. 58]. КНР активно догоняет США в технологической сфере и начинает составлять конкуренцию в ней. В последние годы доля Китая в мировых расходах на НИОКР составляла $23 \%$, у США $25 \%$. Резко возросли публикационная активность Китая в области естественных наук (доля КНР - 20\%, США - 18\% за период 2016-2018 гг. [48]) и количество патентных заявок (40\% общемировых в 2017 г.) [49]. На 2017 г. доля КНР в мировом производстве компьютеров и электроники составила $41 \%$, продукции общего машиностроения - $36 \%$, электротехники 47\% и более половины выпуска мобильных телефонов в мире [49, р. 70-71].

Сохранение технологического лидерства важно для США и с точки зрения экспортных доходов. Поскольку одним из важнейших источников их внешних доходов являются патентные и лицензионные платежи и высокотехнологический экспорт (порядка 376 млрд долл. или 19\% всего экспорта в 2017 г., по данным Observatory of Economic Complexity и The Global Economy [45; 50]), то риски потери технологического лидерства в долгосрочном периоде создают угрозы еще большего ухудшения дефицита текущего счета платежного баланса и, следовательно, макроэкономической стабильности страны.

Китай увеличивает не только свое экономическое, но и политическое влияние на третьи страны за счет внешних интеграционных инициатив. С момента объявления инициативы "Пояса и пути" инвестиционная и кредитная экспансия КНР ускорилась. Посредством множества крупных инфраструктурных проектов, источником финансирования которых в основном являются китайские банки и компании, Китай значительно масштабировал свое влияние на постсоветском пространстве, в Азии, Океании и Африке.

Считалось, что тесная экономическая взаимосвязанность Китая и США должна ослабить политическое противостояние двух стран. Рост сотрудничества в области глобального управления (в том числе через "Группу двадцати") после глобального финансового кризиса рассматривался отдельными учеными как признак снижения рисков противостояния. Однако это все же не смогло предотвратить стратегический конфликт [51].

В администрации США стало приходить понимание, что слишком тесное сотрудничество с КНР может угрожать национальным интересам. Если при администрации Б. Обамы внешнеполитическая стратегия Вашингтона в отношении Пекина совмещала элементы сдерживания (containment) и вовлечения (engagement), то приход к власти Д. Трампа сопровождался переходом к более открытой и системной конфронтации. Например, в Стратегии национальной безопасности 2015 г. было заявлено, что Америка “приветствует рост стабильного и процветающего Китая", [52, р. 24], однако в аналогичном документе 2017 г. уже открыто подчеркивалось, что Китай является ревизионистским государством, которое бросает вызов интересам и мощи США [53].

Итак, КНР превращается в серьезного конкурента США, что для последнихв ближайшие годы означает риски потери глобального лидерства особенно в высокотехнологической сфере. Соответствующей санкционной реакции Китаю следовало ожидать вне зависимости от претензий Соединенных Штатов в области нарушения китайскими компаниями прав интеллектуальной собственности и событий 2020 г. Таким образом, процесс разъединения экономик двух стран был неизбежен в силу упомянутых фундаментальных факторов исчерпания модели созависимости экономик, глубинных изменений в экономике Китая и перехода стран к стратегической конкуренции. 
Безусловно, тесная взаимосвязанность КНР и США выступает демпфером резкого обрыва контактов. Со стороны экспертного сообщества и бизнеса нередко звучат сообщения о невыгодности и потерях от расплетения связей, а также отсутствии серьезных планов по решорингу. По некоторым оценкам, потеря доступа к китайскому рынку полупроводников будет стоить США от 54 до 124 млрд долл., рынка услуг коммерческой и воздушной авиации - около 51 млрд долл. в год, а потеря доли рынка медицинского оборудования - примерно 38 млрд долл. и 100 тыс. рабочих мест в индустрии химической промышленности [54]. По данным China Business Climate Survey Report 2020, который выпускает Торговая палата США, 83\% американских компаний не имеют планов по релокализации производств, расположенных в КНР, $8 \%$ задумывались над этим, но не предприняли никаких шагов, и лишь 9\% начали предпринимать подобные шаги [55]. Существенный же пятикратный разрыв в заработных платах с США на 2018 г. ${ }^{7}$ обеспечивающий более низкие издержки американским компаниям, также является важным аргументом в пользу сохранения сотрудничества с КНР. Тем не менее, процесс расхождения в определенных сферах и секторах экономики по объективным причинам неотвратим и в зависимости от новых внешних обстоятельств может ускоряться или замедляться. Собственно, пандемийно-предвыборный 2020 г. способствовал его ускорению.

$$
* * *
$$

Период пандемии обнажил уязвимые места китайско-американских отношений. Расхождение экономик КНР и США распространялось на все большее количество сфер двустороннего взаимодействия, и если ранее бизнес-логика превалировала над стратегическим соперничеством, то теперь политические мотивы имеют гораздо большее значение, чем экономические [3].

Проведенный в работе анализ демонстрирует, что обострение конкуренции не следствие кризиса, а результат накопленных за годы сотрудничества нерешенных противоречий, связанных с фундаментальными изменениями экономики КНР, мировой экономики в целом. Несмотря на все еще высокую степень взаимозависимости Китая и США, сложившаяся за долгие годы модель сотрудничества исчерпала себя. Процесс расхождения экономик двух стран определяется фундаментальными факторами исчерпанием модели созависимости экономик, глубинными изменениями в экономике Китая, а также переходом стран к стратегической конкуренции. Именно эти факторы послужили главной причиной разъединения, которое лишь катализировалось в 2020 г. на фоне пандемии и президентских выборов в США.

Ограничительные меры, подталкивающие к разрыву, исходят в первую очередь от США, но происходит это из-за внутренних изменений в экономике Китая - смены модели экономического развития и постепенного выхода на лидирующие позиции в мировой экономике (в том числе, обеспечение технологического лидерства КНР). При этом в США компенсирующиеизменениямоделинепроисходят, что обостряетвперспективепроблемы американской экономики (проблемы дефицита бюджета и торгового баланса, высокого уровня госдолга). Ключевой аспект разрыва - это взаимодействие по инновационным и технологическим отраслям, которое будет иметь серьезные последствия для мира в целом. Тот факт, что вводимые санкции в США закрепляются на законодательном уровне, говорит о том, что элементы политики расхождения институционализируются и приобретают долгосрочный характер. Опросы общественного мнения демонстрируют наихудшее отношение американцев к КНР с 1979 г. [56], а в стратегических документах все чаще фиксируется негативный настрой сторон по отношению друг к другу. КНР, в частности, обозначила дестабилизирующее влияние США в Белой книге по обороне в 2019 г. [57], а США упоминают Китай как стратегического конкурента в Национальной стратегии обороны 2018 г. [58] В этом смысле пандемия также продолжает эти тренды: в частности, летом 2020 г. появился стратегический документ "Укрепление Америки и противодействие глобальным угрозам", подготовленный группой республиканцев [59]. В нем авторы предлагали свои способы борьбы с наиболее агрессивными противниками

7 Расчеты на основе данных национального бюро статистики КНР и ОЭСР [42; 43]. 
США в мире, к группе которых был причислен и Китай. В свою очередь, готовность КНР дать отпор США была продемонстрирована высокопоставленным китайским дипломатом Ян Цзечи на встрече в Анкоридже [60].

Предпринимаемые США и КНР действия, которые выглядят как обострение соперничества, по сути являются способом продвижения сторонами их новой роли в мировой экономике. Представляется, что в сложившихся условиях Китай и США в большей степени будут полагаться на себя и на диверсификацию партнеров, чем друг на друга. Китай теперь вынужден осуществлять более ранний переход от технологических заимствований к собственным инновациям или поиску альтернативных источников передовых технологий, таких, как европейские страны.

Для США пандемия, возможно, станет как раз тем триггером, который повлияет на изменение стабильно низкого уровня внутренних сбережений и скорректирует гипертрофированные объемы потребления, не обеспеченные реальным ростом доходов. Это ускорит разрыв созависимости экономик.

Отсутствие ясности по перспективам разрыва $и$ его масштабам создает дополнительные риски для выстраивания международного сотрудничества, включая санкционные риски. В этом смысле отслеживание направлений и темпов расхождения экономик КНР и США как отдельного феномена дает возможность для его серьезного осмысления и выработки механизмов купирования возникших структурных рисков, которые будут иметь последствия не только для КНР и США, но и для мировой экономики в целом.

\section{СПИСОК ЛИТЕРАТУРЫ / REFERENCES}

1. Cooley A., Nexon D. How Hegemony Ends. The Unraveling of American Power. Foreign Affairs, 2020, JulyAugust. Available at: $h$ ttps://www.foreignaffairs.com/articles/united-states/2020-06-09/how-hegemony-ends (accessed 20.02.2021).

2. Тимофеев И.Н. Администрация США против КНР. Российский совет по международным делам, 26.06.2020. [Timofeev I.N. USA Administration Against China. Russian Council for International Affairs. 26.06.2020. (In Russ.)] Available at: https://russiancouncil.ru/analytics-and-comments/analytics/ administratsiya-ssha-protiv-knr/ (accessed 15.02.2021).

3. Rachman G. The Decoupling of the US and China Has Only Just Begun. Financial Times, 17.08.2020. Available at: https://www.ft.com/content/9000d2b0-460f-4380-b5de-cd7fdb9416c8 (accessed 15.02.2021).

4. Nye J. For the US and China, Interdependence Is a Double-Edged Sword. Financial Times, 04.02.2020. Available at: https://www.ft.com/content/b3f5e946-4441-11ea-9a2a-98980971c1ff (accessed 17.02.2021).

5. Ломанов А.В. Китай ответил Западу стратегически. Россия в глобальной политике, 2021, № 3(109), вып. Циркуляция против изоляции, сс. 1-10. [Lomanov A.V. China Responded to the West Strategically. Russia in Global Affairs, 2021, no. 3(109), Circulation vs. Insulation, pp. 1-10. (In Russ.)] Available at: https://globalaffairs. ru/articles/czirkulyacziya-protiv-izolyaczii// (accessed 10.05.2021).

6. Rose G. Neoclassical Realism and Theories of Foreign Policy. World Politics, 1998, no. 51(1), pp. 144-172.

7. Gilpin R. War and Change in World Politics. Cambridge, Cambridge University Press, 1981. 272 p.

8. Zakaria F. From Wealth to Power: The Unusual Origins of America's World Role. Princeton, Princeton University Press, 1998. $216 \mathrm{p}$.

9. Taliaferro J.W. State Building for Future Wars: Neoclassical Realism and the Resource-Extractive State. Security Studies, 2006, vol. 15, no. 3, pp. 464-495.

10. Schweller R. Unanswered Threats: Political Constraints on the Balance of Power. Princeton, Princeton University, 2006. $200 \mathrm{p}$.

11. Ripsman N.M., Taliaferro J.W., Lobell S.E. Neoclassical Realist Theory of International Politics. Oxford University Press, 2016. 208 p.

12. Shrestha G. Chinese Foreign Policy Decision-Making: A Neoclassical Realist Approach. University of Central Oklahoma, 2011. 140 p.

13. Zakaria F. From Wealth to Power: The Unusual Origins of America's World Role. Princeton, Princeton University Press, 1998. $82 \mathrm{p}$.

14. The U.S.-China "Phase One" Deal: A Backgrounder. U.S.-China Economic and Security Review Commission. 04.02.2020. Available at: https://www.uscc.gov/sites/default/files/2020-02/U.S.-China\%20Trade\%20Deal\%20 Issue\%20Brief.pdf (accessed 20.02.2021).

15. Findings of the Investigation into China's Acts, Policies, and Practices Related to Technology Transfer, Intellectual Property, Andinnovation under Section 301 of the Trade Act of 1974. Office of the United States Trade Representative. 2018, March 22. Available at: $h$ ttps://ustr.gov/sites/default/files/Section 301 FINAL.PDF (accessed 20.02.2021).

16. Лексютина Я.В.Американо-китайские отношения в 2018-2019гг.: торговая война и процессдекаплинга. Мировая экономика и международные отношения, 2020, т. 64, № 6, cc. 85-93. [Leksyutina Ya.V. USA- 
China Relations in 2018-2019: Trade War and Decoupling Process, Mirovaya ekonomika I mezhdunarodnye otnosheniya, 2020, vol. 64, no. 6, pp. 85-93. (In. Russ.)] DOl: 10.20542 / 0131-2227-2020-64-6-85-93

17. Lim D., Ferguson D. Conscious Decoupling: The Technology Security Dilemma. China Dreams (China Story Yearbook 2019). Golley J., Hillman B., Jaivin L., Strange Sh., eds. ANU Press, 2019. 10 p. Available at: https:// ssrn.com/abstract=3484171 (accessed 20.02.2021).

18. Review of Controls for Certain Emerging Technologies. Bureau of Industry and Security (US Department of Commerce). Federal Register, 2018, no. 83 (223), pp. 58201-58202.

19. Chinese Investment in the US. Available at: https://www.aei.org/china-tracker-home/ (accessed 10.03.2021).

20. China Global Investment Tracker. American Enterprise Institute. Available at: https://www.aei.org/chinaglobal-investment-tracker/ (accessed 10.03.2021).

21. Kwan C.H. The China-US Trade War: Deep-Rooted Causes, Shifting Focus and Uncertain Prospects. Asian Economic Policy Review, 2020, vol. 15, no. 1, p. 55-72.

22. Кашин А.Б., Зайцев А.А. Китайский успех в борьбе за Европу. Россия в глобальной политике, 2021 № 3(109), cc. 100-105. [Kashin A.B., Zaitsev A.A. Chinese Success in the Fight for Europe. Russia in Global Affairs, 2021, no. 3(109), pp. 100-105. (In Russ.)] Available at: https://globalaffairs.ru/articles/kitajskij-uspeh-vborbe-za-evropu/ (accessed 10.05.2021).

23. Breuninger Q. Trump Says U.S.-China Relationship Is 'Severely Damaged,' Phase 2 Trade Deal Not a Priority. CNBC, 10.07.2020. Available at: https://www.cnbc.com/2020/07/10/trump-says-us-china-relationshipdamaged-phase-2-trade-deal-not-a-priority.html (accessed 21.02.2021).

24. Campbell K.M., Doshi R. The Coronavirus Could Reshape Global Order. China Is Maneuvering for Internationa

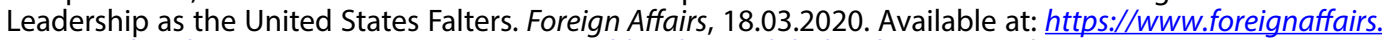
com/articles/china/2020-03-18/coronavirus-could-reshape-global-order (accessed 18.02.2021).

25. Lee M. At Nixon Library, Pompeo Declares China Engagement a Failure. Washington Post, 24.07.2020. Available at: https://www.washingtonpost.com/world/national-security/at-nixon-library-pompeo-declareschina-engagement-a-failure/2020/07/23/c4b073f2-cd29-11ea-99b0-8426e26d203b story.html (accessed 20.02.2021).

26. Is the US Seeking to Decouple from China. Global Times, 25.11.2019. Available at: $h$ ttps://www.globaltimes, cn/content/1171165.shtml (accessed 22.02.2021).

27. 刘程辉. 美财长又提中美经济“脱钩”, 换了个说法. 观察者, 24.06.2020. [US Treasury Secretary Reiterated the "Gap" between the Economies of China and the United States and Changed His Mind. Guanchazhe Media, 24.06.2020. (In Chin.)] Available at: https://www.guancha.cn/ internation/2020 $06 \quad 24 \quad 555271.5 h t m l$ (accessed 22.02.2021).

28. 中国外交部通知美方全闭美国驻成都总领事馆. 24.07.2020. [Chinese Foreign Ministry Informs US of Closure of US Consulate in Chengdu. 24.07.2020. (In Chin.)] Available at: $h$ ttps://www.fmprc.gov.cn/web/ zyxw/t1800357.shtml (accessed 20.02.2021).

29. 外交部宣布中方对美国一机构及4名个人实施对等制裁. 13.07.2020. [Ministry of Foreign Affairs Announced that China Will Impose Retaliatory Sanctions on One US Agency and 4 US Citizens. 13.07.2020 (In Chin.)] Available at: https://finance.sina.com.cn/world/gicj/2020-07-13/doc-iivhvpwx5124493.shtml (accessed 20.02.2021).

30. 商务部新闻发言人就中国将建立“不可靠实体清单”制度答记者问. 商务部专题新闻发布会. [Ministry of Commerce Spokesman Answers Journalists' Questions about China`s "List of Untrustworthy Organizations" System. Special Press Conference of Ministry of Commerce]. Available at: http://www. mofcom.gov.cn/xwfbh/20190531.shtml (accessed 19.02.2021).

31. Кашин В.Б., Пятачкова А.С., Смирнова В.А., Аксенов И.В. Китай в состоянии экономической войны: весна и лето 2020. Аналитическая записка К3/09/2020. ЦКЕМИ НИУ ВШЭ, 2020.23 c. [Kashin V.B., Pyatachkova A.S., Smirnova V.A., Aksenov I.V. China in an Economic War: Spring and Summer 2020. Analytical Note K3/09/2020. TsKEMI NIU VShE, 2020. (In Russ.)] Available at: $h$ ttps://cceis.hse.ru/data/2020/09/14/15833312276/\%D0\%A1\% D0\%B0\%D0\%BD\%D0\%BA\%D1\%86\%D0\%B8\%D0\%B8 \%D0\%B7\%D0\%BO\%D0\%BF\%D0\%B8\%D1\%81\%D0\%B A\%D0\%B0 \%D0\%9A\%D0\%B8\%D1\%82\%D0\%B0\%D0\%B9.pdf (accessed 19.02.2021).

32. Продажа сегмента TikTok США. TACC, 05.12.2020. [Sale of the US TikTok Segment. TASS, 05.12.2020. (In Russ.)] Available at: https://tass.ru/prodazha-segmenta-tiktok-ssha (accessed 27.02.2021).

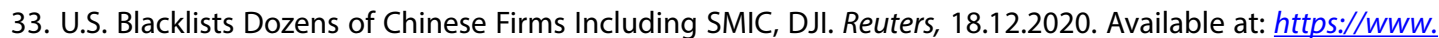
reuters.com/article/us-usa-china-sanctions-idUSKBN28SOHL (accessed 19.02.2021).

34. Government Bans 59 Mobile Apps Which Are Prejudicial to Sovereignty and Integrity of India, Defence of India, Security of State and Public Order. Press Information Bureau Government of India, 29.06.2020. Available at: https://pib.gov.in/PressReleseDetailm.aspx?PRID=1635206 (accessed 19.02.2021).

35. США приветствуют отказ Великобритании от использования Нuawei в создании 5G-сетей. Голос Америки, 15.07.2020. [The US welcomes the UK's abandonment of Huawei for $5 \mathrm{G}$ networks. The Voice of America, 15.07.2020. (In Russ.)] Available at: https://www.golosameriki.com/a/us-state-secretary-pompeowelcomes-uk-decision-to-quit-5g-by-huawei/5503389.html (accessed 27.02.2021).

36. Великобритания изымет оборудование Huawei из инфраструктуры для сетей 5G. Ведомости, 14.07.2020. [The UK Will Withdraw Huawei Equipment from the Infrastructure for $5 \mathrm{G}$ Networks. Vedomosti, 14.07.2020. (In Russ.)] Available at: https://www.vedomosti.ru/technology/news/2020/07/14/834559huawei-5g (accessed 27.02.2021).

37. Роуч С. Несбалансированные. Созависимость Америки и Китая. Москва, Изд-во Института Гайдара, 2019. 515 c. [Rouch S. Unbalanced. The Codependency of America and China. Moscow, Izd-vo Instituta Gaidara, 2019. 515 p. (In Russ.)]

38. China. Observatory of Economic Complexity (OEC). Available at: https://oec.world/en/profile/country/chn (accessed 28.02.2021).

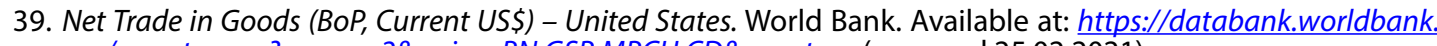
org/reports.aspx?source=2\&series=BN.GSR.MRCH.CD\&country= (accessed 25.02.2021). 
40. United States Government Debt. Trading Economics. Available at: https://tradingeconomics.com/unitedstates/government-debt (accessed 28.02.2021).

41. Zhang L., Brooks R., Ding D., Ding H., Hui He, Jing Lu, Mano R. China's High Savings: Drivers, Prospects, and Policies. IMF Working Paper, 2018, WP/18/277. Available at: $\underline{\text { http://www.iberchina.org/files/2019/savings }}$ china fmi.pdf (accessed 28.02.2021).

42. National Bureau of Statistics of China. Available at: http://www.stats.gov.cn/english/Statisticaldatal AnnualDatal (accessed 28.02.2021).

43. Average Annual Wages. OECD. Available at: https://stats.oecd.org/index.aspx?DataSetCode=AV AN WAGE (accessed 28.02.2021).

44. Current account balance (BoP, Current US\$) - China. World Bank. Available at: $h$ ttps://databank.worldbank.org/ reports.aspx?source $=2 \&$ series $=B N . C A B . X O K A . C D \&$ country $=($ accessed 28.02.2021).

45. Service Trade. OEC. Available at: https://oec.world/en/profile/country/chn (accessed 28.02.2021).

46. 十四五”规划和2035远景目标的发展环境、指导方针和主要目标. 新华社，05.03.2021. [(The Two Sessions are Authorized to Issue) the Development Environment, Guidelines and Main Objectives of the 14th Five-Year Plan and the 2035 Vision. Xinhua, 05.03.2021. (In Chin.)] Available at: http://www.xinhuanet. com/politics/2021/h/2021-03/05/c 1127172897.htm (accessed 28.02.2021).

47. Personal Saving Rate. FRED. Available at: $h$ ttps://fred.stlouisfed.org/series/PSAVERT (accessed 28.02.2021).

48. Тебин Н.П. Китай покорил вершину публикационной активности. Независимая газета, 08.09.2020. [Tebin N.P. China Has Conquered the Peak of Publication Activity. Nezavisimaya gazeta, 08.09.2020. (In Russ.)] Available at: https://www.ng.ru/science/2020-09-08/10 7958 china.html (accessed 28.02.2021).

49. Дмитриев С.С. Американо-китайское технологическое соперничество: от "высокомерия" к бойкоту. Мировая экономика и международные отношения, 2020, т. 64, № 12, cc. 70-77. [Dmitriev S.S. US-China Technological Rivalry: From Arrogance to Boycott. Mirovaya ekonomika i mezhdunarodnye otnosheniya, 2020, vol. 64, no. 12, pp. 70-77 (In Russ.)] DOI: 10.20542/0131-2227-2020-64-12-70-77

50. High Tech Exports - Country Rankings. Available at: https://www.theglobaleconomy.com/rankings/High tech exports/ (accessed 28.02.2021).

51. Luckhurst J. China-US Economic Cooperation as Antidote to Strategic Conflict. G20 since the Global Crisis. New York, Palgrave Macmillan, 2016, pp. 215-247.

52. National Security Strategy. February 2015. Available at: $h$ ttps://obamawhitehouse.archives.gov/sites/default/ files/docs/2015 national security strategy 2.pdf (accessed 25.02.2021).

53. National Security Strategy of the United States of America. December 2017. Available at: https:// trumpwhitehouse.archives.gov/wp-content/uploads/2017/12/NSS-Final-12-18-2017-0905.pdf (accessed 25.02.2021)

54. Martin E. China Decoupling Would Cost U.S. Billions, Chamber Says. Bloomberg, 17.02.2021. Available at: https://www.bloomberg.com/news/articles/2021-02-17/china-decoupling-would-cost-u-s-economy-billionschamber-says (accessed 28.02.2021).

55. 2020 Business Climate Survey Released. Available at: https://www.amchamchina.org/press/2020-businessclimate-survey-released/ (accessed 28.02.2021).

56. Americans' Views on China Go from Bad to Worse. The Wall Street Journal, 04.03.2021. Available at: $h$ ttps:// www.wsj.com/articles/americans-negative-views-on-china-spike-polls-show-11614870001 $\quad$ (accessed 28.02.2021).

57. Huang C. China Takes Aim at the US for the First Time in its Defence White Paper. South China Morning Post, 07.08.2019. Available at: $h$ ttps://www.scmp.com/comment/opinion/article/3021273/china-takes-aim-us-firsttime-its-defence-white-paper (accessed 28.02.2021).

58. Summary of the 2018National Defense Strategy of The United States of America. Available at: $h t t p s: / / d o d . d e f e n s e$. gov/Portals/1/Documents/pubs/2018-National-Defense-Strategy-Summary.pdf (accessed 28.02.2021).

59. Korybko A. The Republican Study Committee's Strategy Document is Antagonistic to China. CGTN, 13.06.2020. Available at: https://news.cgtn.com/news/2020-06-13/The-Republicans-strategy-document-isantagonistic-to-China-RinqJG6wF2/index.html (accessed 28.02.2021).

60. Дипломаты США и Китая обвинили друг друга в нарушении протокола в Анкоридже. Коммерсантъ, 19.03.2021. [US and Chinese Diplomats Accused Each Other of Violating Protocol in Anchorage. Kommersant, 19.03.2021. (In Russ.)] Available at: https://www.kommersant.ru/doc/4733448 (accessed 28.02.2021). 


\title{
COVID-19 CRISIS AS A CATALYST FOR THE USA-CHINA DECOUPLING
}

\section{(Analysis and Forecasting. IMEMO Journal, 2021, no. 2, pp. 13-27)}

\author{
Received 09.04.2021. \\ Accepted 01.06.2021.
}

Alexander A. ZAITSEV (alex.zaytsev@hse.ru), ORCID:0000-0002-5428-709X,

National Research University Higher School of Economics, 20, Myasnitskaya Str., Moscow 101100, Russian Federation.

Anastasia S. PYATACHKOVA (apyatachkova@hse.ru), ORCID: 0000-0001-7319-2371, National Research University Higher School of Economics, 20, Myasnitskaya Str., Moscow 101100, Russian Federation.

Acknowledgements. The reported study was funded by RFBR and EISR, project number 20-01131821 "World politics and economy megatrends in the context of a global systemic crisis: models and strategies for Russia".

The Sino-American rivalry has increased during the pandemic. The ongoing decoupling is rather sectoral than comprehensive and is reflected in trade and sanctions war, competition, restrictions in such spheres as technologies, investment, science, and education.

The contradictions are caused not by the pandemic context, but stem from the fundamental structural problems in Sino-American cooperation associated with a change of the economic development model in China and the absence of compensatory mechanisms in the United States, as well as the transition of countries to the phase of strategic competition.

From a formal point of view, it looks like the confrontation was mainly initiated by the United States, but it was China that first revealed the intention to greater independence. It is associated with the Chinese economy's qualitative changes - restructuring of the growth model from export towards domestic demand and Chinese leadership claims in a number of high-tech industries. All this made cooperation with China disadvantageous and not safe (in the sense of economic security) for the United States.

The 2020 pandemic accelerates natural processes, and the arrival of the new Biden administration will not change their overall direction: the trend towards breaking ties in a number of areas will continue, despite the presence of interested parties, especially in the business sector. But the high economic interdependence still determines the gradual and long-term nature of the decoupling process.

Decoupling also has some important consequences for other countries, which, in the context of a strategic confrontation between the two powers, may be faced with the need to choose one of the partners. In the future, some countries may also benefit due to the restructuring of the ChineseAmerican value chains.

Keywords: COVID-19 pandemic, trade war, US-China relations, sanctions war, competition.

About the authors:

Alexander A. ZAITSEV, Cand. Sci. (Econ.), Deputy Head of the Asia-Pacific Sector, Centre for Comprehensive European and International Studies, Higher School of Economics.

Anastasia S. PYATACHKOVA, Cand. Sci. (Econ.), Research Fellow, Deputy Head of the International Economic Research Sector, Centre for Comprehensive European and International Studies, Higher School of Economics.

DOI: 10.20542/afij-2021-2-13-27 